\title{
SISTEMAS DE ESPAÇOS LIVRES URBANOS: CONSTRUINDO UM REFERENCIAL TEÓRICO
}

\author{
QUEIROGA, Eugenio Fernandes \\ Doutor em Arquitetura e Urbanismo pela FAUUSP; Professor Titular da FAU-PUC-Campinas; Professor do \\ Programa de Pós-Graduação em Urbanismo da PUC-Campinas; Professor Doutor da FAUUSP. \\ E-mail: queiroga@usp.br
}

\section{BENFATTI, Denio Munia}

Doutor em Urbanismo e Planejamento Urbano; pelo Institut D'Urbanisme de Paris - Université de Paris XII Professor Titular da FAU-PUC-Campinas; Professor do Programa de Pós-Graduação em Urbanismo da PUC-Campinas. E-mail: Pos.urb@puc-campinas.edu.br

\section{RESUMO}

Em qualquer que seja a formação urbana, das menores cidades às megalópoles, o reconhecimento sistêmico do conjunto de espaços livres de cada uma delas se constitui em si, importante fator para a análise, interpretação, proposição e gestão dos espaços livres, notadamente para os espaços públicos. Relacionam-se os conceitos de espaço, lugar, paisagem, esfera de vida pública, espaço público e espaço livre. Não se trata de buscar definições rígidas, mas de construir um quadro conceitual que fundamente o método de uma pesquisa sobre sistemas de espaços livres urbanos brasileiros, tendo como dois de seus objetivos futuros contribuir para a formulação de princípios para o projeto de um sistema de espaços livres e para a visão sistêmica do projeto de um espaço livre.

\section{Palavras-chave: Espaço e paisagem, sistemas de espaços livres, esfera pública, teoria e método.}

\section{ABSTRACT}

To recognize the systemic character of the open spaces of the cities constitutes an important factor to the analysis, interpretation, proposition and management of the open space, mainly to the public spaces, in any urban formation, from the smaller cities to the megalopolis. The concepts of space, place, landscape, public life sphere, public space and open space become related. It is not proposes rigid definitions, but to construct concepts to base the method to a research about Brazilians urban open spaces, it's having two of theirs futures objectives to contribute to a formulation of principles to the project of a system of open spaces and to the systemic vision of the project of an open space.

\section{Key words: Space and landscape, systems of open spaces, public sphere, theory and method.}

\section{Introdução}

Desde os primórdios da existência das cidades os espaços livres urbanos vêm se constituindo em importante elemento para a vida citadina. Ruas, largos, praças, páteos, quintais, jardins privados e públicos, parques, avenidas, entre os mais freqüentes tipos de espaços livres, formam o sistema de espaços livres de cada cidade, de cada metrópole ou dos novos territórios urbanos, próprios da recente reestruturação produtiva, exópoles, megalópoles, metápoles, ou, simplesmente, territórios de urbanização difusa.

Em qualquer que seja a formação urbana, ocidental ou oriental, das menores cidades às megalópoles, o reconhecimento sistêmico do conjunto de espaços livres de cada uma delas se 
constitui em si, importante fator para a análise, diagnóstico, proposição e gestão dos espaços livres, notadamente para os espaços públicos.

As transformações recentes na base técnica, realizadas em escala global, muito vem alterando o meio. Como Milton Santos (1996a) afirmou, estamos diante de um meio técnico-científicoinformacional. Compreender os diversos papéis, atuais e potenciais, dos sistemas de espaços livres urbanos neste novo período é tarefa complexa e vasta, onde pouco vale amplas generalizações. $\bigcirc$ que se observa e se presta para uma cidade norte-americana, pode não ser útil para uma cidade brasileira, ainda que de mesmo porte; tão pouco o sistema de espaços livres de uma cidade média gaúcha possui grande semelhança com o de uma cidade amazônica, ainda que de dimensões similares.

Com o objetivo de investigar os sistemas de espaços livres no país, estruturou-se um projeto temático de pesquisa intitulado "Os sistemas de espaços livres e a constituição da esfera de vida pública contemporânea no Brasil". Tal projeto conta com a participação e colaboração de vários pesquisadores, de todas as regiões do país. Iniciam-se esforços para a discussão sobre diferenças e similaridades de estruturações, concepções, gestões e apropriações entre os sistemas de espaços livres de algumas dezenas de cidades e regiões metropolitanas brasileiras. Destaca-se a abordagem, dialética e sistêmica, sem receio da heterodoxia, assimilando visões complementares que possibilitem, pela natureza do objeto investigado, um amplo arco de visadas sobre o tema. Afirma-se como abordagem dialética e sistêmica aquela formulada por Milton Santos, portanto, ao empregar-se a expressão "dialética e sistêmica" não há aqui nenhuma referência à abordagem sistêmica da geografia física.

Apresenta-se neste ensaio uma discussão sobre parte da conceituação básica que fundamenta a referida pesquisa, constituindo um referencial teórico que, pela abrangência, pode se prestar a outros trabalhos na área. Relacionam-se a seguir os conceitos de espaço, lugar, paisagem, esfera de vida pública, espaço público e espaço livre. Não se trata de buscar definições rígidas, mas de constituir um quadro conceitual que fundamente os princípios de método a serem adotados nesta investigação sobre sistemas de espaços livres brasileiros.

\section{Espaço e lugar}

Tem-se como principal referência a geografia nova de Milton Santos. Parte-se do entendimento do espaço como totalidade, como uma instância social, ao mesmo nível das demais instâncias - economia, cultura, ideologia e política -; desta maneira a dialética social não se estabelece apenas no espaço, mas se realiza com o espaço. Compreende-se o espaço como um conjunto indissociável de sistemas de objetos e sistemas de ações. Desta postura decorrem os elementos gerais de uma análise espacial dialética e sistêmica: os fixos e fluxos, a paisagem e a sociedade, as horizontalidades e verticalidades, a tecnoesfera e a psicoesfera, os embates entre o lugar e o mundo (SANTOS, 1996a), entre as racionalidades hegemônicas e comunicacionais na constituição dos lugares (QUEIROGA, 2001).

Os elementos ativos do espaço são os homens, as empresas e as instituições, que produzem o meio técnico-científico-informacional sobre as dinâmicas do suporte bio-físico. Trata-se de uma produção heterogênea, mesmo em tempos de globalismos econômico-ideológicos, pois o espaço se apresenta como um prático-inerte sartreano (SANTOS, 1996a), como uma herança, diferenciando os lugares diante de sua maior ou menor capacidade de resistência e potência para a assimilação das inovações e ordens hegemônicas; as culturas são produzidas historicamente, mas também geograficamente.

O lugar, categoria interna e analítica do espaço (SILVA, 1986), se constitui como espaço da co-presença, do acontecer solidário (SANTOS, 1996a) - organizacional e orgânico. Os lugares são onde se realizam as ordens globais, mas são, também, espaços de resistência, onde colidem 
as diferentes racionalidades, sistêmicas e comunicacionais (HABERMAS, 1981); constituem-se, na dialética da cotidianidade (HELLER, 1970), espaço para a surpresa.

Sobre os lugares se estabelecem relações topofílicas (TUAN, 1974), geografias da afetividade. Milton Santos (1996a) também não exclui a emotividade da análise geográfica, pelo contrário, a emoção se apresenta como elemento próprio ao lugar, ao cotidiano e com isso participa da dialética entre o lugar e o mundo, lugar e espaço total, lugaridade e totalidade.

\section{Espaço e paisagem}

A paisagem pode ser considerada como resultante das relações entre processos sociais e processos naturais (MAGNOLI, 1982). A paisagem é também um sistema "... na medida em que, a partir de qualquer ação sobre ela impressa, com certeza haverá uma reação correspondente, que equivale a uma alteração morfológica parcial ou total" (MACEDO, 1999). A paisagem é, portanto, sempre dinâmica, ou, nas palavras de Milton Santos (1988): "a paisagem é a acumulação desigual do tempo".

Concorda-se com Santos quando afirma que paisagem e espaço não são sinônimos, o espaço - total - apresenta categorias analíticas internas: o lugar, a região, o território e a paisagem. Porém, sobretudo para a área de paisagismo, é preciso avançar para além da noção santosiana da paisagem. Segundo Milton Santos (1996b) a paisagem é trabalho morto, passado, somente o espaço é presente. O autor associa a paisagem ao sistema de objetos, cabendo apenas ao espaço um valor ativo, sistema de objetos e de ações. Para Santos (1996a) "a rigor, a paisagem é apenas a porção da configuração territorial que é possível abarcar com a visão... A paisagem é, pois, um sistema material e, nessa condição, relativamente imutável, o espaço é um sistema de valores, que se transforma permanentemente".

Reduzir a paisagem a um sistema material, à dimensão visível dos sistemas de objetos não permite apreender, sobretudo na escala do lugar, toda a dimensão qualitativa desta "visibilidade" que caracteriza a noção de paisagem. O sistema de ações - integrante do espaço - ao se realizar, qualifica a paisagem, se visualiza direta ou indiretamente nas diferentes paisagens. Para um mesmo sistema de objetos, podemos ter diferentes estados da paisagem, exatamente quando nele se realizam diferentes sistemas de ações, além da evidente questão da periodicidade em que se estabelecem os fenômenos naturais (noite e dia, chuva e sol, verão e inverno, entre outros).

Uma paisagem urbana como a da Avenida Paulista em São Paulo, apresenta diferentes estados - "situ-ações", ela é uma nos dias de semana e outra aos domingos, é uma nas situações do cotidiano de trabalho, é outra em dias de manifestações políticas. Não se pode abstrair da paisagem da Paulista a presença física maior ou menor das pessoas e dos veículos, se assim se procedesse, se abdicaria da própria leitura visual daquela paisagem, para não se falar de seus significados. As ações, dos homens, empresas e instituições, não apenas são parte integrante do espaço - total - como se manifestam na paisagem, constituindo-as; lê-las permite compreender melhor a fisionomia e a estrutura processual da paisagem, possibilitando, também, propor com maior consciência sobre seus processos formadores.

As paisagens não somente abrigam os eventos resultantes dos sistemas de ações, como por eles se qualificam e, dialeticamente, os especificam. Neste sentido pode-se aproximar da noção proposta por Péguy (1957) de "paisagem-evento". Propõe-se a compreensão da paisagem como um sistema de objetos - em uma dada porção contínua do espaço - em interação dialética com um sistema de ações, presente na referida parcela do espaço. Tem-se, portanto, que a paisagem é parte sensorialmente apreensível do espaço-total e apresenta-se, tal qual o espaço, com valor ativo no processo social.

Para se ler a paisagem não basta uma "visão de sobrevôo" (MERLEAU-PONTY, 1945), é necessário, segundo Péguy (1957), uma visão de baixo, de dentro da paisagem e em movimento. 
É preciso perceber a paisagem, num primeiro momento fenomenológico, "desarmado" de categorias analíticas estabelecidas aprioristicamente, evitando-se "pré-juízos", deixar-se surpreender. Conforme Besse (2000), em ensaio sobre a filosofia e a paisagem de Péguy, é preciso "experimentar a paisagem"; ou, no sentido metodológico preconizado por Bergson (1959), "intuir" qualitativamente a paisagem, muito mais do que induzir ou deduzir. Este é o primeiro e não menos importante momento da compreensão da paisagem.

Num segundo momento - de natureza geográfica stricto sensu - pode-se ler a paisagem buscando compreender as relações entre os processos que a engendram, neste nível analítico a teoria santosiana do espaço é fundamental, busca-se a inserção da paisagem nos sistemas gerais que dialeticamente constituem o espaço. Não se pode compreender a paisagem isoladamente, abstraí-la da "formação sócio-espacial" (SANTOS, 1978) seria grave equívoco.

âmbito paisagístico stricto sensu constitui-se num terceiro nível analítico, onde a compreensão da paisagem não abdica da análise morfológica (MACEDO), inclusive "morfométrica", como diria Vladimir Bartalini, para a compreensão do sistema de objetos. Neste nível analítico a paisagem não é reduzida à sua materialidade, mas enfatiza-se a leitura sobre seus aspectos sensorialmente perceptíveis, cotejados ao sistema de objetos que constitui sua fisionomia. A compreensão da fisionomia da paisagem inclui o entendimento das relações ecológicas, em maior ou menor grau impactadas pelo sistema de ações (dos homens, empresas e instituições). Neste âmbito paisagístico de análise, busca-se reconhecer relações entre formas, usos, impactos e valorações, inclusive aspectos estéticos da construção humana da paisagem e a valorização estético-cultural das paisagens pelos grupos sociais a elas relacionados.

Num quarto momento - de natureza paisagística lato sensu - pode-se interpretar a paisagem, num movimento de sínteses, a partir da evocação de sentidos - aesthesis - para os distintos grupos sociais em interação com o entendimento das formas espaciais concretas, das diversas apropriações pelos diferentes homens, empresas e instituições, abrangendo seus significados simbólicos, suas representações. Avança-se na compreensão dos processos de semiose da paisagem, suas significações mais profundas, complexas e contraditórias, caminha-se para além da "visualidade", da aparência da paisagem, busca-se a "visibilidade" (FERRARA, 2002) de sua existência.

Têm-se, neste caminho metodológico, condições para a compreensão crítica da paisagem e para contribuições propositivas sobre ela. Estabelece-se um saber processual, capaz de permitir, nesta sucessão heterodoxa e não linear de aproximações à paisagem, conhecimento que tencione e transgrida as posições de objetividade ou subjetividade de leitura da paisagem, quiçá no caminho de superá-las.

\section{A esfera de vida pública}

A esfera de vida pública é própria da vita activa (ARENDT, 1958), da ação política, entendida em sentido amplo, envolve a produção cultural e a construção da cidadania. Na esfera pública as diferenças e divergências têm possibilidade de se apresentar através dos discursos comunicativos (visando o entendimento mútuo, uma verdade processual), daí decorrendo o acordo político em seu sentido maior, a noção de interesse público, de bem público, constituído socialmente diante do conflito de interesses. $O$ bem público não se confunde com a noção de bem comum, o primeiro é fruto da construção dialética da política, o segundo, se produz enquanto ideologia da classe dominante.

A esfera pública se constitui no domínio da liberdade, da instância cultural; a esfera privada se relaciona, primordialmente, ao domínio das necessidades, portanto, da instância econômica. Mas nem tudo que está além da esfera de vida privada se constitui na esfera pública, a sociedade capitalista contemporânea não apenas fortaleceu a esfera de vida privada como, também, 
reforçou uma esfera social. Esta esfera se caracteriza por acessos restritos a determinados grupos sociais, onde o mundo do negócio e do ócio se produz, em boa medida, para além da vida privada e aquém da vida pública.

Não se trata de um simples declínio do homem público, mas de uma metamorfose da esfera pública (HABERMAS, 1962). Importante compreender os novos modos, escalas e significados para a vida pública. Na contemporaneidade afirma-se, inclusive, a internet como meio para sua expressão. Também necessário admitir que a noção de público pode, em muitas circunstâncias, não se constituir como uma esfera universal, há que se compreendê-la como um sistema, onde grupos sociais não apenas constituem esferas sociais de vida, mas podem constituir, também, públicos fragmentados. A esfera de vida pública se constitui numa rede complexa de conexões entre esferas de públicos específicos que se estabelecem em determinados momentos, o que não elimina o indivíduo de participar de diversos grupos sociais, não apenas identificados por sua classe social. O mundo não se pauta apenas pelas relações entre capital e trabalho, o que não significa afirmar que tais relações não tenham importância. Um indivíduo pode participar de um sindicato, apenas como contribuinte; de uma ONG contra a prostituição infantil, dedicando algumas horas por semana; de uma escola de samba, somente na noite de seu desfile; realizando, portanto, ações públicas de diversas escalas e naturezas.

Os novos meios informacionais e telecomunicacionais não homogeneízam as sociedades. No Brasil, a apropriação privada da "res-pública" vem marcando nossa história desde o período colonial (LEITE, 1998). Constrói-se uma nação de cidadania incompleta, uma esfera pública peculiar. É necessário investigá-la dialeticamente. Compreender o papel dos espaços livres públicos na atualidade contribui para o entendimento de algumas espacialidades concretas da esfera de vida pública, tarefa possível à área de Paisagismo, trabalho mais profícuo, porém, se aberto a contribuições de outras áreas do conhecimento. Base para o projeto de espaços livres públicos mais atentos à sua dimensão sistêmica, às demandas e potencialidades dos lugares contemporâneos.

\section{Os espaços públicos e os espaços livres: uma abordagem sistêmica}

As novas tecnologias alteram as relações de produção e consumo. Buscam-se compreender as novas relações espaciais, ou sócio-espaciais, é por esta ótica que Santos (1994) formula o conceito de meio técnico-científico-informacional. Propõe-se, em extensão ao raciocínio santosiano, a expressão meio técnico-científico-informacional e comunicacional, na medida em que tal meio potencializa, dialeticamente, o estabelecimento da ação comunicativa habermasiana. $\mathrm{Na}$ densidade maior de técnicas e ciências, o meio propicia maior intensidade informativa e comunicativa, permitindo a fluidez das ordens informativas, próprias da verticalidade espacial (SANTOS, 1996), mas também a razão comunicativa, por vezes pública, própria da horizontalidade espacial (QUEIROGA, 2001), possibilita-se uma esfera pública mais intensa.

O espaço público é aqui entendido não apenas como suporte físico - sistema de objetos - onde se realizam as ações da esfera pública, mas como espaço da esfera pública - sistema de objetos e de ações da esfera pública. Denomina-se "espacialidade pública" não apenas aquela de propriedade pública (os bens de uso comum do povo, ruas, praças, parques, os imóveis do poder público, escolas públicas, os postos de saúde, os terminais municipais, etc), mas todos os lugares nos momentos onde se realizarem ações da esfera pública. Podem ser públicos, neste sentido, espaços livres ou edificados, de propriedade pública ou privada, desde uma padaria paulistana, um boteco carioca, uma praia em Florianópolis, uma Igreja em Belém, um Terreiro em Salvador, um estádio particular de futebol em dia de "clássico" estadual, um CTG - Centro de Tradições Gaúchas - em Sorocaba ...

Ao conjunto de espacialidades públicas de uma dada área urbana, verifica-se a produção de diversas relações entre seus elementos, constituindo num sistema de espaços voltados à esfera 
pública. Trata-se de um sistema bastante dinâmico, dele fazendo parte certo sistema de objetos, com maior ou menor freqüência, em função dos eventos públicos neles incidentes.

Os espaços livres urbanos, como Miranda Magnoli (1982) já definira, são os espaços livres de edificação; todos eles: quintais, jardins públicos ou privados, ruas, parques, rios, mangues e praias urbanas, etc. Tais espaços formam, nas palavras de Catharina Pinheiro (2004) um "tecido pervasivo", sem o qual não se concebe a existência das cidades, estão por toda parte, mais ou menos processados e apropriados pela sociedade; constituem, quase sempre, o maior percentual do solo das cidades brasileiras. Todos os espaços livres urbanos são objeto de interesse da área de paisagismo, indo, portanto, muito além dos jardins (MAGNOLI, 1982).

Os espaços livres urbanos formam um sistema, apresentando, sobretudo, relações de conectividade, complementaridade e hierarquia. Entre seus múltiplos papéis, por vezes sobrepostos, estão a circulação, a drenagem, atividades do ócio, convívio público, marcos referenciais, memória, conforto e conservação ambiental, etc. O sistema de espaços livres de cada cidade apresenta um maior ou menor grau de planejamento e projeto prévio, um maior ou menor interesse da gestão pública num ou noutro sub-sistema a ele relacionado.

A noção de sistema de espaços livres aqui adotada abrange um escopo muito maior que o do "sistema de áreas verdes". Espaços livres e áreas verdes freqüentemente ainda se confundem no Brasil; muito em função da cultura anglo-saxônica na área de paisagismo, presente nos quadros técnicos e acadêmicos do país, que privilegia os parques e demais áreas verdes e nem sempre observa a maior complexidade dos sistemas de espaços livres urbanos. A cultura urbanística e paisagística de origem inglesa e norte-americana tem como um grande valor a presença do verde, as áreas exclusivamente residenciais de baixa densidade, os bairros jardins, os subúrbios em meio ao verde, a cidade jardim howardiana. Tais valores em muito influenciam não apenas quadros técnicos governamentais e acadêmicos, como estão, de fato, bastante presente na produção de paisagens habitacionais para os extratos de maior renda. As qualidades destes padrões urbanos precisam ser confrontadas com seus aspectos negativos, de mesma forma, reconhecer valores em padrões mais tradicionais de nossa cultura latina são esforços que requerem atenção numa pesquisa sobre sistemas de espaços livres nas cidades brasileiras.

Os espaços livres urbanos constituem um sistema complexo, dada a inter-relação com outros sistemas urbanos que podem se justapor ao sistema de espaços livres (sistema de objetos edificados e seu correspondente sistema de ações) ou se sobrepor, total ou parcialmente, enquanto sistemas de ações. Neste último caso, interessa particularmente investigar as principais interrelações entre o sistema de espaços livres e o sistema de espacialidades públicas nas áreas urbanas brasileiras, em que medida os sistemas de espaços livres contribuem para a produção da esfera pública contemporânea. Evidentemente, diante da diversidade urbana brasileira não haverá uma resposta simples, mas bastante rica, complexa e diversa para o quadro nacional. O desafio está lançado.

\section{Bibliografia}

ARENDT, Hannah. A condição humana. Tradução de Roberto Raposo. 5. ed. Rio de Janeiro: Forense Universitária, 1991.

BERGSON, Henry-Louis. Oeuvres. Paris: Presses Universitaires de France, 1959.

BESSE, Jean-Marc. Voir la terre: Six essais sur le paysage et la géographie. Arles: Actes Sud/ENSP, 2000.

CERTEAU, Michel de. Artes de fazer. A invenção do cotidiano. Tradução de Ephraim Alves. 2. ed. Petrópolis: Vozes, 1996.

FERRARA, Lucrécia. Design em espaços. São Paulo: Rosari, 2002. 
FOUCAULT, Michel. Microfísica do poder. Organização e tradução de Roberto Machado. 14. ed. Rio de Janeiro: Graal, 1999.

HABERMAS, Jürgen. Mudança estrutural da esfera pública: Investigações quanto a uma categoria da sociedade burguesa. Tradução de Flávio Kothe. Rio de Janeiro: Tempo Brasileiro, 1984.

. Lifeworld and system: A critique of funcionalist reason. The theory of communicative action. Tradução de Thomas $\overline{M c C a r t h y . ~ B o s t o n: ~ B e a c o n ~ P r e s s, ~ v . ~ 2, ~} 1989$.

HELLER, Agnes. O cotidiano e a história. Tradução de Carlos Nelson Coutinho e Leandro Konder. 4. ed. Rio de Janeiro: Paz e Terra, 1996.

LEITE, Maria Ângela. As tramas da segregação. 1998. Tese (Livre-Docência) - Faculdade de Arquitetura e Urbanismo, Universidade de São Paulo, São Paulo, 1998.

MACEDO, Sílvio. Quadro do paisagismo no Brasil. São Paulo: FAUUSP, 1999.

MAGNOLI, Miranda. Espaços livres e urbanização: Uma introdução a aspectos da paisagem metropolitana. 1982. Tese (Livre-Docência) - Faculdade de Arquitetura e Urbanismo, Universidade de São Paulo, São Paulo, 1982.

MERLEAU-PONTY, Maurice. Phénomenologie de la perception. Paris: Gallimard, 1994.

PÉGUY, Charles. Ouvres en prose - 1909-1914. Paris: Gallimard, 1957.

QUEIROGA, Eugenio. A megalópole e a praça: O espaço entre a razão de dominação e a ação comunicativa. 2001. Tese (Doutorado em Arquitetura e Urbanismo) - Faculdade de Arquitetura e Urbanismo, Universidade de São Paulo, São Paulo, 2001.

SANTOS, Milton. Sociedade e espaço: A formação social como teoria e como método. Tradução de Maria Beltrão. Boletim Paulista de Geografia, São Paulo, n. 54, p. 81-99, 1977. . A natureza do espaço: Técnica e tempo, razão e emoção. São Paulo: Hucitec, 1996.

Da paisagem ao espaço uma discussão. In: II ENCONTRO NACIONAL DE ENSINO DE PAISAGISMO EM ESCOLAS DE ARQUITETURA E URBANISMO, 1996, São Paulo. Anais..., São Paulo: Unimarco, 1996.

. Metamorfoses do espaço habitado. São Paulo: Hucitec, 1988.

SILVA, Armando. As categorias como fundamentos do conhecimento geográfico. In: SANTOS, Milton; SOUZA; Maria Adélia de (Coords.). O espaço interdisciplinar. São Paulo: Nobel, 1986.

TUAN, Yi-fu. Topofilia: Um estudo da percepção, atitudes e valores do meio ambiente. São Paulo: Difel, 1980. 